\title{
A Case of Endoscopic Reduction of Isolated Maxillary Sinus Posterior Wall Fracture Using Foley Catheter
}

\author{
Ho Jun Lee ${ }^{D}$ and Ki Joon Park $\mathbb{D}$ \\ Department of Otorhinolaryngology-Head and Neck Surgery, Chuncheon Sacred Heart Hospital, College of Medicine, \\ Hallym University, Chuncheon, Korea \\ 부비동 내시경 수술 기법과 폴리도뇨관을 이용한 상악동 후벽 단독골절에 대한 치험 1예 \\ 이호준 · 박기준 \\ 한림대학교 의과대학 춘천성심병원 이비인후-두경부외과학교실
}

\author{
Received August 16, 2020 \\ Revised November 3, 2020 \\ Accepted November 4, 2020 \\ Address for correspondence \\ Ho Jun Lee, MD \\ Department of Otorhinolaryngology- \\ Head and Neck Surgery, \\ Chuncheon Sacred Heart Hospital, \\ College of Medicine, \\ Hallym University, 77 Sakju-ro, \\ Chuncheon 24253, Korea \\ Tel +82-33-240-5180 \\ Fax +82-33-241-2909 \\ E-mail leehj@hallym.or.kr
}

The surgical goal for reduction of maxillofacial fracture has been focused on the reconstruction of facial buttresses. If there is fracture-displacement at non-buttress area, it close observation used to be the choice of treatment. It is not easy to have access to the posterior part of maxilla with conventional approach. But with the endoscopic sinus surgery technique, posterior wall of maxillary sinus is easily approachable and can be manipulated. This report presents a case of a 38-year-old male with isolated posterior wall of maxillary sinus fracture. Inward comminuted fracture-displacement of the posterior wall of maxillary sinus with retroantral fat and soft tissue was herniated into the maxillary sinus and extruded out through the natural ostium of maxillary sinus. Using endoscopic approach and Foley catheter inflation, the maxillary sinus posterior wall was successfully repaired without complications. This report thus suggests endoscopic approach with the Foley catheter for the posterior maxillary sinus wall fracture. Korean J Otorhinolaryngol-Head Neck Surg 2021;64(10):746-50

Keywords Foley catheterization; Maxillary fractures; Transnasal endoscopic surgery.

\section{Introduction}

Among various types of facial bone fracture, isolated maxillary sinus wall fracture is rare, and is accounted for $1.3 \%$ of facial bone fracture. ${ }^{1)}$ The most common site of maxillary sinus wall fracture is the anterior wall because the traumatic force is generally coming from the front in traumatic episode. In certain conditions, isolated maxillary sinus posterior wall fracture can be identified.

In case of isolated maxillary sinus posterior wall fracture, close observation can be considered if the degree of fracture is minimal. However, when the degree of fracture is signifi-

This is an Open Access article distributed under the terms of the Creative Commons Attribution Non-Commercial License (https://creativecommons.org/licenses/by-nc/4.0) which permits unrestricted non-commercial use, distribution, and reproduction in any medium, provided the original work is properly cited. cant, complications such as hypoesthesia, maxillary sinusitis can be developed if the appropriate surgical reduction is not provided. ${ }^{2)}$ The therapeutic plans for maxillary sinus posterior wall fracture are rarely reported because of its rarity in practice and its difficulty to approach the posterior part of maxilla with the conventional open approach.

In this report, authors present the case of a patient with isolated maxillary sinus posterior wall fracture. The patient was successfully treated with the endoscopic approach through maxillary natural ostium and by applying Foley catheter inflation.

\section{Case}

A 38-year-old male visited the emergency room, suffering from right facial pain after a slip down and bumping his face 
onto the ground. Initial physical examination showed bruising of both eyes, and tenderness at the right cheek. Non-enhanced facial computed tomography (CT) was conducted on the day he got injured. The findings revealed isolated right maxillary sinus posterior wall fracture without accompanying any other facial bone fractures. Comminuted fracture of maxillary sinus posterior wall was identified and the bony fragments were dislocated inwardly, $15 \mathrm{~mm}$ apart from its base. Natural ostium of maxillary sinus and ethmoid infundibulum were obstructed by herniated retroantral soft tissue (Fig. 1). Conservative management was done for four days, and the operation was held on the fifth day after the injury.

Under general anesthesia, right uncinectomy and middle meatal antrostomy was performed. The right maxillary sinus was filled with hematoma, herniated retroantral fat and soft tissue. After the irrigation and removal of hematoma, bony fragments of posterior wall of maxillary sinus was identified. Herniated retroantral soft tissue was reduced using curved instruments while preserving Schneiderian membrane. Bony fragments of posterior wall of maxillary sinus was rearranged underneath the preserved Schneiderian membrane. To sustain the reduced state of retroantral soft tissue, and to fix the rearranged position of bony fragments, 12 French Foley catheter was inserted through widened maxillary sinus natural ostium and its balloon was inflated (Fig. 2). Inflated Foley catheter balloon was left in the maxillary sinus. The rest part of Foley catheter beneath the balloon was cut and removed from nasal cavity. In order to sustain the inflation state of Foley catheter balloon, plastic tube with long ligature (ENDOLOOP ${ }^{\circledR}$ Ligature, J\&J Medical Devices, New Brunswick, NJ, USA) was applied at 2 points just beneath the balloon before cutting the Foley catheter. Final shape of Foley catheter used in this procedure was illustrated in Fig. 3. The stump of residual Foley catheter was positioned in the middle meatus. During the surgery, exposed vessels were not identified and there was no active bleeding from the branches of maxillary artery.

The patient was discharged from the hospital 2 days after the surgery, and the Foley catheter in the maxillary sinus was removed 4 weeks after the surgery at the outpatient clinic. Postoperative CT scans showed a successful outcome (Fig. 4).

\section{Discussion}

\section{Suggested mechanism of isolated maxillary sinus posterior wall fracture}

Simonds, et al. ${ }^{3)}$ proposed mechanism for isolated maxillary sinus posterior wall fracture. When the patient bump the ipsilateral mandibular body, mandibular condyle is dislocated from temporomandibular joint (TMJ) and coronoid process rotate anteromedially, hitting the ipsilateral posterior maxillary sinus wall. This may cause fractures of mandible or persistent dislocation of condyle. However, in this present case, there was no definite fracture of mandible; the condyle was reduced spontaneously into the TMJ; and there was no sign of malocclusion. Consequently, the patient got an isolated maxillary sinus posterior wall fracture.

\section{Management of isolated maxillary sinus posterior wall fracture}

As isolated maxillary sinus posterior wall fractures don't
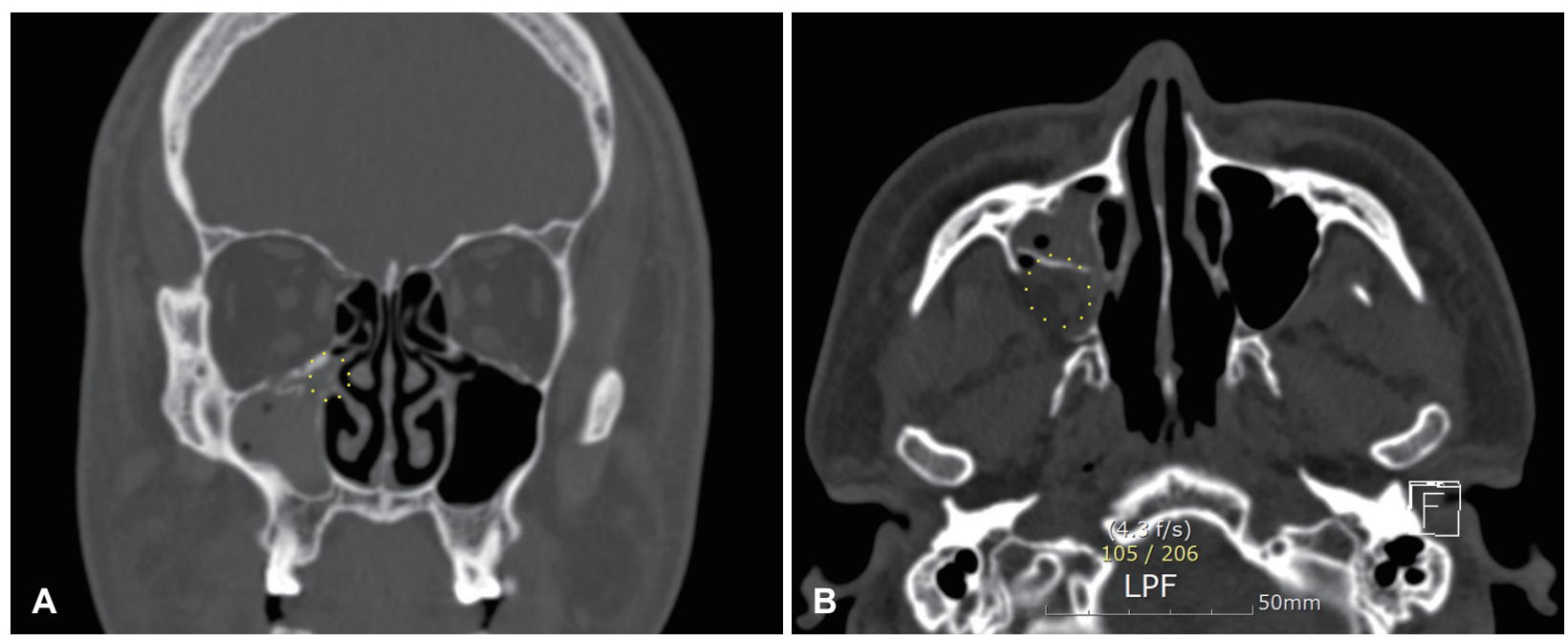

Fig. 1. A 38-year-old male with isolated maxillary sinus posterior wall fracture. Coronal section of facial bone CT. Right ethmoid infundibulum was obstructed by retroantral soft tissue herniation (A). Axial section of facial bone CT. Fractured segments were about $15 \mathrm{~mm}$ apart from its base. Herniated retroantral soft tissue (yellow dots) was identified (B). 

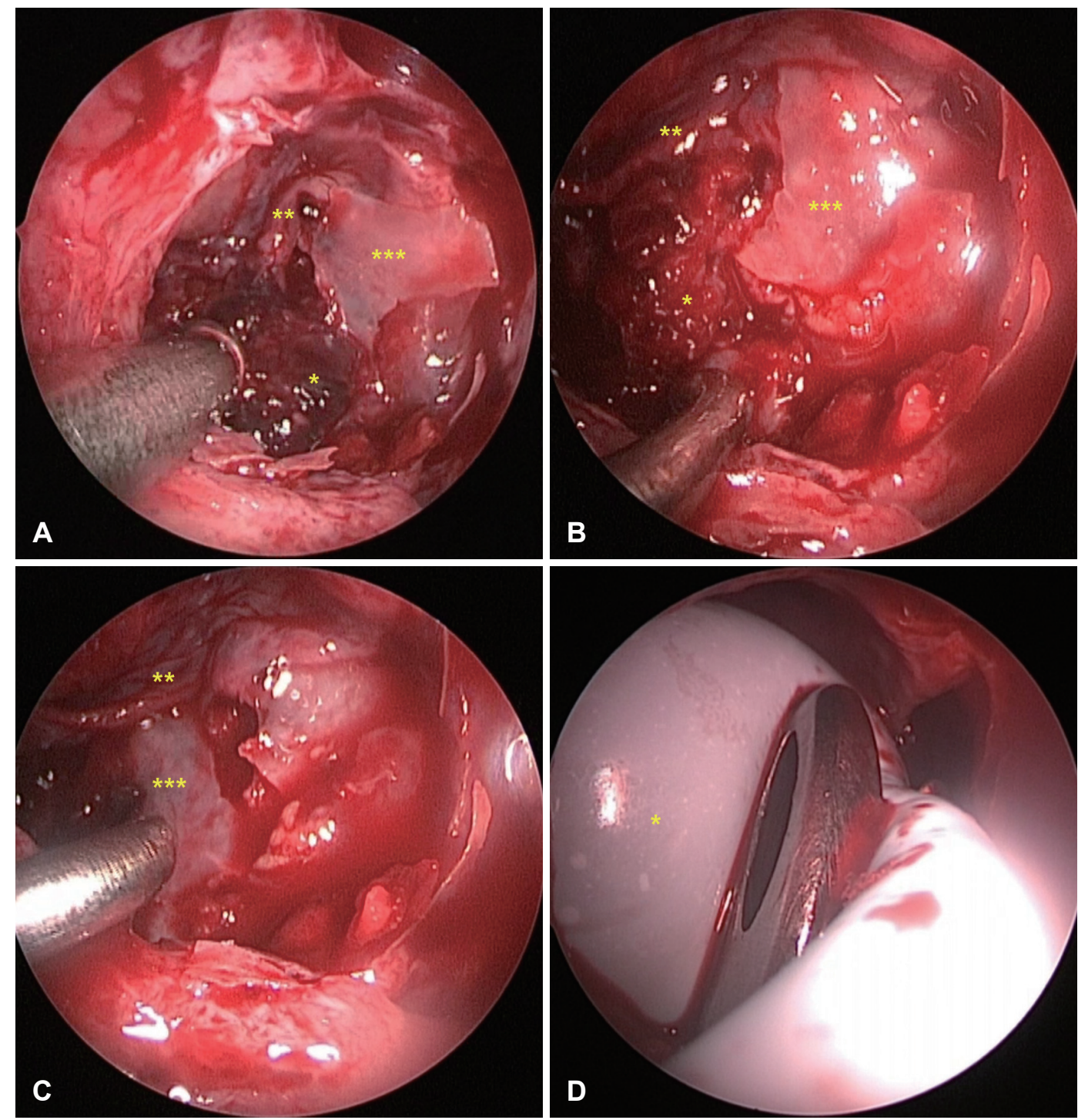

Fig. 2. Intraoperative photograph. After uncinectomy, hematoma $\left.{ }^{*}\right)$, torn Schneiderian membrane $\left(^{* *}\right)$ and fractured bony fragments $\left({ }^{* * *}\right)$ were seen $(A)$. After the removal of hematoma, herniated content of pterygopalatine fossa(*), Schneiderian membrane $\left({ }^{* *}\right)$ and fractured bony fragments $\left(^{* * *}\right)$ were identified $(B)$. Bony fragments of maxillary sinus posterior wall( $\left.{ }^{* * *}\right)$ was relocated underneath the Schneiderian membrane $\left(^{* *}\right)(\mathrm{C}) .12$ French Foley catheter $\left(^{*}\right)$ was inflated and the reduction of maxillary sinus posterior wall was done (D).

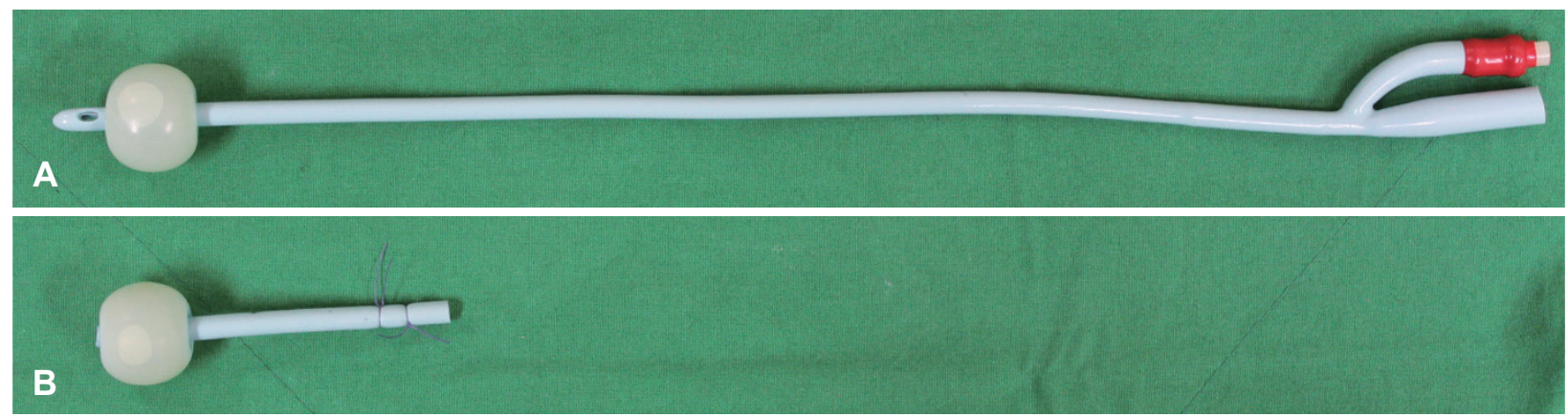

Fig. 3. Modification of Foley catheter for maxillary sinus posterior wall reduction. The original shape of 12 French Foley catheter, ballooned with $20 \mathrm{~mL}$ normal saline (A). The final shape of 12 French Foley catheter designed for reduction and fixation of maxillary sinus posterior wall. The tip of Foley catheter was cut and the balloon part was positioned in the maxillary sinus. Endoloop ligature was applied beneath the balloon. The rest part of Foley catheter beneath the endoloop tie was removed and the stump was located in middle meatus (B). 

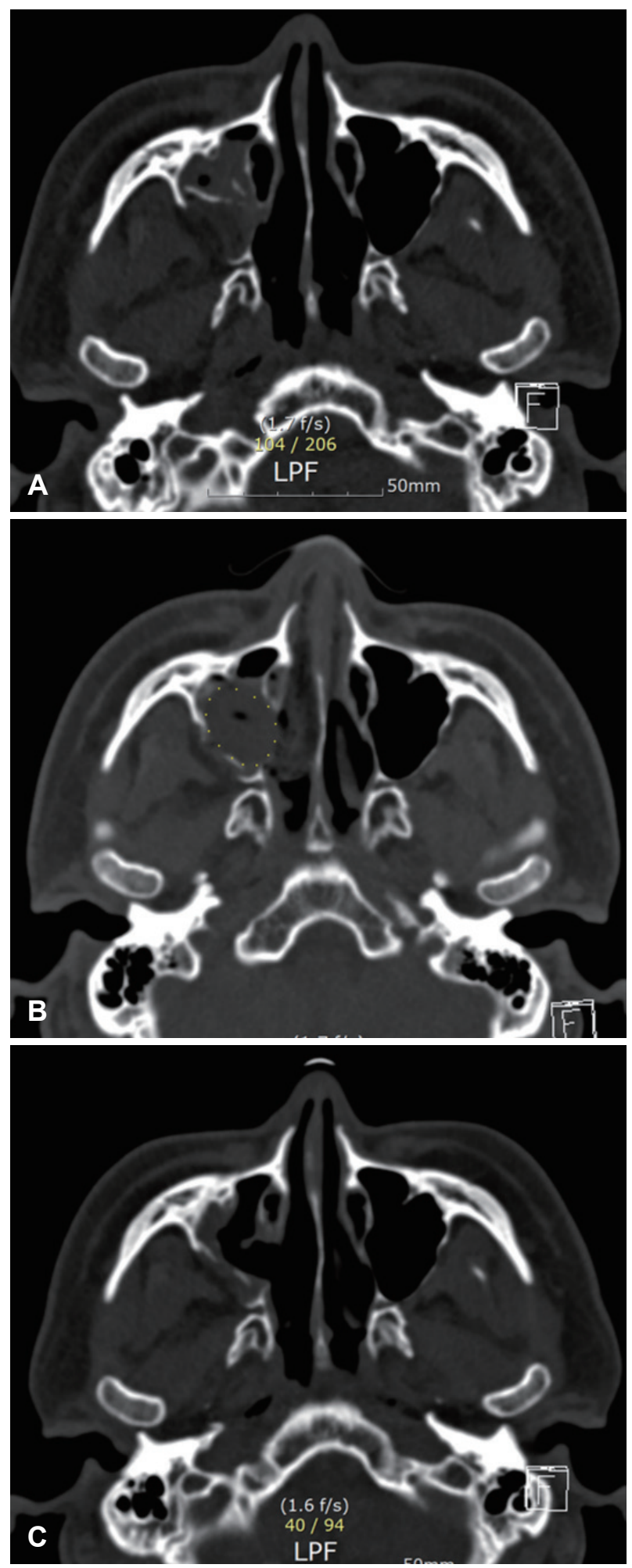

Fig. 4. Preoperative and postoperative CT scan. Preoperative CT scan. Fracture of posterolateral wall of right maxillary sinus (A). Immediate postoperative CT scan. Reduction of right maxillary sinus posterior wall using 12 French Foley catheter, $20 \mathrm{~mL}$ normal saline inflation (yellow dots) (B). Postoperative 4 weeks follow up CT scan. Foley catheter balloon was removed at the outpatient clinic. CT scan shows successful reduction and good aeration of maxillary sinus $(C)$. usually affect the external appearance of the face, conservative management has been preferred to the open surgical reduction. However, in this case, the authors thought proper management was needed because there was a definite obstruction of ethmoidal infundibulum due to the herniated retroantral fat and soft tissues. Without an appropriate reduction, not only sinusitis can occur but also there is a risk of hypoesthesia and the pain around innervated parts of pterygopalatine ganglion and maxillary nerve. ${ }^{4)}$ Moreover, if the patient is undergoing sinus surgery involving maxillary sinus in the future, there would also be an increased risk of iatrogenic complication.

\section{The surgical technique}

Facial bone fracture reduction using Foley catheter is not a new concept and has been used in the past by other surgeons in maxillary sinus anterior wall fractures and inferior orbital blow out fractures. ${ }^{5)}$ However, this case report has some new information. To the best of our knowledge, there has been no report which introduces the surgical reduction of isolated maxillary sinus posterior wall fracture. We believe our therapeutic modality is simple and that it can be easily adopted by the endoscopic sinus surgeons. This case report would be helpful for facial trauma surgeons who encounter this kind of rare case.

Some may raise questions about the reason why we restore maxillary sinus posterior wall using fractured bony fragments instead of just removing it. The authors believe that the reduction of maxillary sinus posterior wall using bony fragments will offer less callus formation and more stable structure. Well reconstructed maxillary sinus posterior wall can better protect the pterygopalatine fossa and keep the natural ostium of maxillary sinus patent. The authors used Foley catheter balloon as a spacer. 12 French Foley catheter balloon can afford more than $30 \mathrm{~mL}$ of saline, which is enough volume to maintain reduction. The authors preferred the Foley catheter balloon to the surgical sponge nasal packings such as Merocel (Medtronic Inc., Minneapolis, MN, USA), because the risk of foreign body infection is thought to be less in silastic material.

This technique can be performed under local anesthesia, but we used general anesthesia in this case. There are two reasons to this. First, there may need a large amount of irrigation to remove hematoma which can be uncomfortable for the patient. Second, to rearrange bony fragments meticulously, maximal cooperation of patient was needed. The authors explained these concerns to the patient, and the patient chose to go under the general anesthesia. 
Contrast enhanced facial CT scans to check the damage of branches of maxillary artery can be meaningful. However, in our case, there was no active epistaxis when we encounter the patient, and there were already examined non-contrast enhanced facial CT which was conducted in the emergency department. The authors kept in mind the possibility of damages of the contents of pterygopalatine fossa, and explained this concerns to the patient, but the contrast enhanced facial CT scan was not performed again. The authors tried to minimize the possible iatrogenic complications during the surgery by using blunt instruments. The usage of microdebrider was avoided as much as possible.

\section{Limitation and advantages of using this surgical method}

Most of maxillary sinus posterior wall fracture accompany with other facial bone fracture. Other part of facial bone fracture may need conventional technique, and cannot be reduced simply with this technique. This kind of reduction technique is useful in maxillary sinus anterior wall fracture, maxillary sinus posterior wall fracture and in some cases of inferior orbital blow out fracture.

The advantages of this manner is clear. First, this technique is easy to be adopted by the endoscopic sinus surgeons, and its operation time is relatively short. This technique can extend the indication of endoscopic sinus surgery. Second, this minimal invasive approach does not leave external scar. Third, the reconstruction of maxillary sinus outflow tract and border of pterygopalatine fossa can prevent sinus problems such as chronic rhinosinusitis, and iatrogenic complication which can be followed in the possible future endoscopic sinus surgery by reconstructing of border of pterygopalatine fossa.

\section{Acknowledgments}

None.

\section{Author Contribution}

Conceptualization: Ho Jun Lee. Data curation: all authors. Formal analysis: all authors. Funding acquisition: Ho Jun Lee. Investigation: Ho Jun Lee. Methodology: Ho Jun Lee. Project administration: Ho Jun Lee. Resources: Ho Jun Lee. Software: Ho Jun Lee. Supervision: Ho Jun Lee. Validation: Ho Jun Lee. Visualization: Ho Jun Lee. Writing — original draft: Ki Joon Park. Writing — review \& editing: Ho Jun Lee.

\section{ORCIDs}

Ho Jun Lee https://orcid.org/0000-0003-3973-3650

Ki Joon Park https://orcid.org/0000-0002-1791-9262

\section{REFERENCES}

1) Hwang K, You SH. Analysis of facial bone fractures: An 11-year study of 2,094 patients. Indian J Plast Surg 2010;43(1):42-8.

2) Perko M. Maxillary sinus and surgical movement of maxilla. Int J Oral Surg 1972;1(4):177-84.

3) Simonds JS, Whitlow CT, Chen MY, Williams DW 3rd. Isolated fractures of the posterior maxillary sinus: CT appearance and proposed mechanism. AJNR Am J Neuroradiol 2011;32(3):468-70.

4) Imai T, Sukegawa S, Kanno T, Fujita G, Yamamoto N, Furuki Y, et al. Mandibular fracture patterns consistent with posterior maxillary fractures involving the posterior maxillary sinus, pterygoid plate or both: CT characteristics. Dentomaxillofac Radiol 2014;43(2): 20130355 .

5) Lee JS, Na YS, Lee JW, Park CH. The successful reduction of an anterior maxillary fracture with Foley catheter and real-time ultrasonography. Korean J Otorhinolaryngol-Head Neck Surg 2014;57(5):340-3. 